\title{
BILATERAL PNEUMO'THORAX WITH PNEUMOMEDIASTINUM UNDER ANAESTHESIA IN A HEALTHY FEMALE
}

\author{
Mooriath Ramachandran, Victor C. Dulay, Zeena A. Lobo and John B. Kuriyan
}

\begin{abstract}
A case of bilateral pneumothorax and pneumomediastinum developing under general anaesthesia without apparent cause is reported. Possible aetiologic factors and mechanisms of the condition are outlined. Clinical signs and the immediate management of pneumothorax and pneumomediastinum are discussed.
\end{abstract}

KEY WORDS: COMPLICATIONS, Lung; pneumothorax, catamenial pneumothorax.

PNeumothorax in the adult is a relatively common condition.' A variety of predisposing and precipitating factors have been reported, including idiopathic subpleural blebs in otherwise healthy young individuals, pulmonary tuberculosis, emphysema, chronic bronchitis, pneumonia, acute upper respiratory infection ${ }^{1,2}$ and malignancy. ${ }^{3}$ Pneumothorax associated with menstruation has also been reported. ${ }^{4-8}$ Pneumothorax is also seen in patients on mechanical ventilatory support. ${ }^{9}$

\section{Case Report}

A 19-year-old white female was admitted for elective tonsillectomy. Her previous medical history was unremarkable. The physical examination was normal. She was $157.5 \mathrm{~cm}$ tall and weighed $47 \mathrm{~kg}$. Preoperative laboratory examination including a chest $\mathrm{x}$-ray was within normal limits.

She was premedicated with morphine sulphate $5 \mathrm{mg}$ and atropine $0.4 \mathrm{mg}$ intramuscularly one hour before the operation. Anaesthesia was induced with thiopentone $200 \mathrm{mg}$ intravenously. Succinylcholine $100 \mathrm{mg}$ was given intravenously for tracheal intubation, which was smooth and

Mooriath Ramachandran, M.D.; Victor C. Dulay, M.D.; Zeena A. Lobo, M.D.; John B. Kuriyan, M.D.; Department of Surgery, Division of Anesthesiology, CMDNJ-Rutgers Medical School, Piscataway, N.J. 08854

Reprints: Mooriath Ramachandran, M.D., Department of Surgery, Division of Anesthesiology, CMDNJ-Rutgers Medical School, Piscataway, NJ 08854 .

Can. Anaesth. Soc. J, vol. 29, no. 4, July 1982 done under full vision with a $7.5 \mathrm{~mm}$ cuffed tracheal tube. After the chest had been auscultated for bilateral breath sounds, a mixture of 60 per cent nitrous oxide and 40 per cent oxygen was started and the lungs were ventilated manually. A continuous drip of succinylcholine 0.1 per cent was started to maintain muscle relaxation. The patient was then positioned for operation. As a mouth gag was being inserted, subcutaneous emphysema was noted in the neck and anterior chest wall and auscultation of the chest disclosed bilaterally diminished air entry. The nitrous oxide was discontinued immediately. A chest $\mathrm{x}$-ray showed bilateral pneumothorax of about 25 to 30 per cent, extensive subcutaneous emphysema and pneumomediastinum with dissection of air into the retroperitoneum. No changes occurred in vital signs or in the electrocardiogram during this time. Number 28 chest tubes were inserted promptly on both sides and good ventilation was noted bilaterally. It was decided to postpone the tonsillectomy. A direct laryngoscopic examination and cervical endoscopy done by the otolaryngologist did not show any evidence of trauma to those areas. Oesophagoscopy and rigid bronchoscopy done by the thoracic surgeon were also negative. During this time anaesthesia was maintained with halothane, oxygen and the succinylcholine drip.

The patient was taken to the recovery room where the trachea was extubated and she was given 40 per cent humidified oxygen by mask. She was then transferred to the intensive care unit alert and oriented. A barium swallow done later in the day was normal. On the third day she was started on a soft diet, which she tolerated 
well. By the third postoperative day the pneumothorax had cleared and the pneumomediastinum cleared by the fourth day. The chest tubes were removed on the seventh and eight days, and she was discharged from the hospital one day later. She was followed after discharge by the thoracic surgery service at the clinic and continued to do well.

\section{Discussion}

Trauma to the upper airway from instrumentation resulting in mediastinal emphysema upon positive airway pressure is one of the first possibilities one considers under these circumstances. Anaesthetic gases under positive pressure can dissect through the mucosal tear in the upper airway into the mediastinum and can, with continued pressure, rupture the mediastinal pleura to produce pneumothorax. ${ }^{10}$ In our case, however, trauma was ruled out with a fair amount of certainty not only because the intubation itself was smooth under full vision, but also because no evidence of trauma could be demonstrated after a thorough examination of the upper airway by endoscopy and barium contrast studies.

Spontaneous pneumothorax has been reported to be relatively common in young, apparently healthy individuals. ${ }^{1}$ In the absence of coexisting pulmonary disease, the commonest cause is a ruptured subpleural bleb. ${ }^{1,2}$ It is possible that, in a predisposed individual, normal levels of positive airway pressure used during general anaesthesia could create a pneumothorax. Marcotte, et al. report a case in which an inflation pressure of $12 \mathrm{~mm} \mathrm{Hg}$ (1.6 kPa) was employed after repair of a pleural rent with subsequent development of subcutaneous emphysema and contralateral pneumothorax. ${ }^{11}$

Spontaneous pneumothorax has also been reported in relation to menstruation. ${ }^{4-8}$ After Maurer first publicized such an episode in 1958 , several more cases of both unilateral and bilater$a^{5,6}$ catamenial pneumothorax have appeared in the literature. Even though commonly associated with ovulatory cycles, this phenomenon has also occurred in patients on ovulation suppressant drugs. ${ }^{6}$

Proposed causative factors for this type of pneumothorax include thoracic endometriosis ${ }^{12}$ and congenital diaphragmatic defects. ${ }^{8}$ These lesions, however, have not been seen in all cases of catamenial pneumothorax. Another proposed mechanism involves the vasoactive substance dinoprost tromethamine, which is elaborated by the endometrium during menstruation. ${ }^{5,7}$ High levels of this substance are found in the menstrual debris and also in the plasma of some patients at the time of menstruation. ${ }^{7}$ Dinoprost tromethamine, which is prostaglandin $F_{2}$, has bronchoconstrictive and vasoconstrictive properties and can damage the alveolar epithelium. Levels of dinoprost tromethamine are higher during ovulatory cycles. ${ }^{13}$

Spontaneous pneumothorax during menstruation has been seen usually in parous women in whom ovulatory cycles are well established and shows a close relationship to the onset of the menstrual flow. Presumably this would be the time when dinoprost tromethamine is at its highest level, with a maximum effect on the alveolar tissue. Our patient was nulliparous and younger than the typical case in the literature. In addition, she was on the third day past her period. The circumstances of development of the pneumothorax also were not typical, since she was being given positive pressure ventilation at the time. It is conceivable that the alveoli, recovering from the damaging effects of dinoprost tromethamine, might be more prone to rupture from the normal inflation pressures used during induction and manual ventilation.

Marginal alveoli in the lung, which lie adjacent to blood vessels, are more prone to rupture since they are not equally supported on all sides by other alveoli. Air leaking from such ruptured alveoli can travel along the perivascular sheaths to the mediastinum. ${ }^{4.15}$ With continued positive pressure and air leakage, mediastinal emphysema can spread; and the mediastinal pleura, which is weaker than the visceral pleura, can rupture causing pneumothorax. ${ }^{16}$ Air might also spread to the subcutaneous tissues of the neck and to the retroperitoneum.

In the absence of subcutaneous emphysema, mediastinal emphysema and pneumothorax can be difficult to detect, especially under anesthesia. Air in the perivascular sheaths of the lung can cause wheezing by compressing the bronchioles. With small amounts of air, characteristic crunching heart sounds can be heard (Hamman's sign). ${ }^{17}$ If sufficient pressure builds up in the mediastinum, compression of the heart and great vessels and compression of the upper airway in the hypopharynx can occur. ${ }^{10} \mathrm{De}$ crease in lung compliance, cyanosis and dis- 
tended neck veins may be seen. Progressive increase in pressure, if unrelieved, can lead to cardiovascular collapse.

Pneumothorax can sometimes produce electrocardiographic changes that may resemble those of an acute anterior myocardial infarction. ${ }^{18}$ In a left-sided pneumothorax there can be a shift of the frontal QRS axis to the right and a decrease in the size of the precordial $R$ wave. However, differentiation from acute myocardial infarction can be made by the absence of $Q$ waves, ST elevation or $\mathrm{T}$ wave inversion. Radiological examination, of course, would confirm the presence of mediastinal emphysema and pneumothorax.

Once a pneumothorax is suspected, prompt treatment is of paramount importance in view of the potential for serious consequences. Nitrous oxide should be discontinued because it rapidly diffuses into closed air-containing spaces, causing increase in the pressure within. A 60 per cent mixture of nitrous oxide, upon equilibration, could increase the pressure within the cavity approximately threefold. Breathing 100 per cent oxygen would also counteract the effects of intrapulmonary shunt due to the collapse of the lung.

Measures to relieve the tension within the pleural cavity should be undertaken promptly. Closed tube thoracotomy should be done as soon as possible. Although it is desirable to document the pneumothorax radiographically, delaying treatment unduly for the sake of $x$-rays is not justified. The chest can be temporarily decompressed by a wide-bore needle and syringe in the second intercostal space anteriorly if a skilled person is not immediately available to insert chest tubes.

Mediastinal emphysema usually resolves spontaneously when the continued positive pressure is stopped and the tension in the pleural cavity is relieved. Breathing a high concentration of oxygen helps the dispersal of pneumomediastinum and surgical emphysema. ${ }^{19}$ If spontaneous resolution does not occur and if signs of mediastinal or upper airway compression persist, surgical decompression should be undertaken by incising the cervical fascia.

In summary, we have presented a case of spontaneous pneumothorax with mediastinal emphysema in young healthy female under anaesthesia. Various causative factors are discussed along with a brief outline of management of the condition. It should be mentioned that such an episode is usually an isolated occurrence and may not pose any additional risk to the patient at subsequent anaesthetics.

\section{REFERENCES}

1. Mattila, S. \& Kostiainen, S. Spontaneous pneumothorax. Scan. J. Thorac. Cardiov. Surg. 11:259 (1977).

2. O'Hara, V.S. Spontaneous pneumothorax. Military Medicine pp. 32, January (1978).

3. LaUCiUs, J.F., Brodovsky, H.S. \& Howe, C.D. Spontaneous pneumothorax and pneumomediastinum as complications of sarcoma. $J$. Thorac. Cardiov. Surg. 64: 467 (1972).

4. Maurer, E.R., Schaal, J.A., \& Mendez, F.L. JR. Chronic recurring spontaneous pneumothorax due to endometriosis of the diaphragm. J. Amer. Med. Ass. 168: 2013 (1958).

5. Laws, H.L., Fox, L.S. \& Younger, J.B. Bilateral catamenial pneumothorax. Arch. Surg. [12: 627 (1977).

6. Wilhelm, J.L. \& Scommegna, A. Catamenial pneumothorax, bilateral occurrence while on suppressive therapy. Surg. Gynec. Obstet. 50: 227 (1977).

7. Rossi, N.P. \& Goplerud, C.P. Recurrent catamenial pneumothorax. Arch. Surg. 109: 173 (1974).

8. Furman, W.R., Wang, K.P., Summer, W.R. \& TERRY, P.B. Catamenial pneumothorax: evaluation of fiberoptic pleuroscopy. Amer. Rev. Resp. Dis. 121: 137 (1980).

9. Estafanous, R.G., VILUOEN, J.F. \& Barsoum, K.N. Diagnosis of pneumothorax complicating mechanical ventilation. Anes. Analg. 54: 730 (1975).

10. Peatfield, R.C., Edwards, P.R. \& Johnson, N. Two unexpected deaths from pneumothorax. Lancet 1: 356 (1979).

11. Marcotte, R.J., Phillips, F.J., Adams, W.E., et al. Differential endobronchial pressures and mediastinal emphysema. J. Thorac. Surg. 9:346 (1940).

12. Crutcher, R.R., Waltuch, T.L. \& Blue, M.E. Recurring spontaneous pneumothorax associated with menstruation. J. Thorac. Cardiov. Surg. 54: 599 (1967).

13. PICKLES, V.R. The menstrual stimulant in puberty. J. Physiol. 183: 69P (1966)

14. MACKLIN, M.T. \& MACKLIN, C.C. Malignant interstitial emphysema of the lungs and mediastinum as an important occult complication in many respiratory diseases and other conditions: an interpretation of the clinical literature in the light of laboratory experiment. Medicine 23: 281 (1944).

15. Martin, J.T. \& Patrick, R.T. Pneumothorax: its significance to the anesthesiologist. Anes. Analg. 39: 420 (1960).

16. SALTET, J.F. Pneumothorax: letters to the editor. Lancet I: 671 (1979).

17. Wintrobe, M.M., et al. Harrison's principles of 
internal medicine, 7th edition. New York McGraw-Hill (1974)

18. Walston, A., Brewer, D.L., Kitchens, C.S. et al. The electrocardiographic manifestations of spontaneous left pneumothorax. Ann. Intern Med. 80: 375 (1974).

19. BoDEY, G.P. Medical mediastinal emphysema. Ann. Intern Med. 54: 46 (1961).

\section{Résumé}

Les auteurs rapportent un pneumothorax bilatéral avec pneumomédiastin survenu sous anesthésie générale sans cause apparente. Les facteurs étiologiques et les mécanismes qui auraient pu produire cette complication sont évoqués. Les signes cliniques et la conduite immédiate à tenir en cas de pneumothorax et de pneumomédiastin sont discutés. 